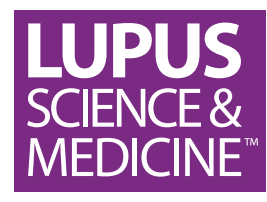

\title{
Association of age with health-related quality of life in a cohort of patients with systemic lupus erythematosus: the Georgians Organized Against Lupus study
}

\author{
Laura Plantinga, ${ }^{1,2}$ S Sam Lim, ${ }^{3}$ C Barrett Bowling, ${ }^{2,4}$ Cristina Drenkard ${ }^{3}$
}

To cite: Plantinga $L$, Lim SS, Bowling $\mathrm{CB}$, et al. Association of age with health-related quality of life in a cohort of patients with systemic lupus erythematosus: the Georgians Organized Against

Lupus study. Lupus Science \& Medicine 2016;3:e000161. doi:10.1136/lupus-2016000161

- Additional material is available. To view please visit the journal (http://dx.doi.org/ 10.1136/lupus-2016000161)

Received 8 April 2016 Revised 24 June 2016 Accepted 27 June 2016

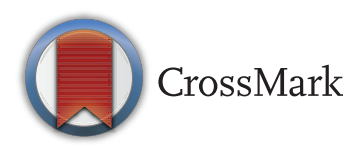

For numbered affiliations see end of article.

Correspondence to Dr Laura Plantinga; laura.plantinga@emory.edu

\section{ABSTRACT}

Objective: To examine whether older age was associated with lower health-related quality of life (HRQOL) among patients with systemic lupus erythematosus (SLE) and whether differential diseaserelated damage and activity explained these associations.

Methods: We used cross-sectional data on 684 patients with SLE aged $\geq 20$ years from the Georgians Organized Against Lupus cohort to estimate the associations between age (categorised as 20-39, 40-59 and $\geq 60$ years) and HRQOL (Short Form-12 norm-based domain and physical component summary (PCS) and mental component summary (MCS) scores), using multivariable linear regression. We then examined the effect of disease-related damage and activity on these associations.

Results: The mean age of the cohort was 48.2 \pm 13.1 years (range, $20-88$ years), with $28.0 \%, 52.9 \%$ and $19.1 \%$ of participants being aged $20-39,40-59$ and $\geq 60$ years, respectively; $79.0 \%$ were AfricanAmerican and $93.7 \%$ were female. The mean PCS score was 39.3 (41.8, 38.7 and 37.4 among those aged $20-39,40-59$ and $\geq 60$ years, respectively), while the mean MCS score was 44.3 (44.2, 43.8 and 46.1, respectively). In general, lower physical but not mental HRQOL scores were associated with older age. With adjustment, older ages (40-59 and $\geq 60$, respectively, vs $20-39)$ remained associated $(\beta(95 \% \mathrm{Cl}))$ with lower PCS $(-2.53(-4.58$ to -0.67$)$ and -3.57 $(-6.19$ to -0.96$))$ but not MCS $(0.47$ (-1.46 to 2.41$)$ and $1.20(-1.52$ to 3.92$))$ scores. Associations of age with $\mathrm{HRQOL}$ domain and summary scores were not substantially changed by further adjustment for disease-related damage and/or activity.

Conclusions: Nearly one in five participants in this large, predominantly African-American cohort of patients with SLE was at least 60 years old. The associations of older age with lower physical, but not mental, HRQOL were independent of accumulated SLE damage and current SLE activity. The results suggest that studies of important geriatric outcomes in the setting of SLE are needed to inform patient-centred clinical care of the ageing SLE population.

\section{INTRODUCTION}

Systemic lupus erythematosus (SLE) was historically considered a disease of young women. ${ }^{1}$ However, as a complex, chronic disease, SLE can also be thought of as analogous to 'geriatric syndromes', ${ }^{2}$ which are multifactorial health conditions that involve morbidity across multiple organ systems and confer susceptibility to poor outcomes, including low health-related quality of life (HRQOL). ${ }^{3}{ }^{4}$ Furthermore, SLE also affects older individuals, ${ }^{5}$ and the increasing pool of older individuals in the US population ${ }^{6}$ who can develop late-onset SLE (up to $18 \%$ of patients with $\mathrm{SLE}^{7}$ ) and longer life expectancy for all patients with $\mathrm{SLE}^{7} 8$ will likely result in a substantial population of older patients with SLE over time. As patients with SLE age, they are likely to accumulate disease-related damage as well as experience changes in SLE activity. Lower HRQOL may be associated with both increased disease activity and greater accumulated damage,$^{9-13}$ although this evidence is not consistent across time or all HRQOL domains. ${ }^{4}{ }^{13}$ However, independent of SLE-specific disease activity and accumulated organ damage, patients with SLE may also experience changes in their HRQOL that are related to age itself.

Despite this, few studies have explicitly examined the independent association of age with HRQOL in SLE. Older age has been shown to be a potential linear predictor of lower HRQOL in patients with SLE, ${ }^{4} 13$ but previous studies of patients with SLE generally have not examined categorisations of age that might reveal important non-linear patterns in the association of HRQOL with age. Knowledge of how HRQOL differs across the lifespan (ie, young, middle-aged 
and older) in this population could support care by providing context for results from clinically recommended assessment of HRQOL. ${ }^{14}$ It is also important to understand to what extent clinical factors such as SLE-associated organ damage and SLE activity, which are also recommended for comprehensive SLE assessment, ${ }^{14}$ drive associations between age and HRQOL. As individuals age, their reported HRQOL may be less related to current health status, ${ }^{15}$ and disease severity may have differential effects with age. For example, in a population-based study, higher degree of renal insufficiency was shown to have disproportionately higher impact on physical aspects of HRQOL, but disproportionately lower impact on mental aspects of HRQOL, among older versus younger adults. ${ }^{16}$ In SLE, similar differential effects may exist, and disease factors are also likely to differ over the lifespan: while SLE-associated organ damage is likely to increase with age, ${ }^{17}$ SLE activity may be lower among the oldest individuals. ${ }^{18}$

Greater understanding of the associations of age with HRQOL-and the relative contributions of cumulative disease damage and disease activity to these associations -may inform this recommended care for patients with SLE of all ages. Furthermore, many previous studies of HRQOL have targeted predominantly white populations, ${ }^{19}{ }^{20}$ despite African-Americans having greater susceptibility to SLE and poorer outcomes of SLE, including greater disease activity and damage. ${ }^{21-25}$ Thus, examining these questions in a cohort with better representation of African-Americans is needed to advance our understanding of the effects of age, disease activity and damage on HRQOL in SLE. Using cross-sectional data from the ongoing, predominantly African-American Georgians Organized Against Lupus (GOAL) cohort, which enrolled large numbers of adult patients with SLE of young, middle and older ages, we examined whether these age categories are independently associated with various domains of HRQOL among patients with SLE and whether these associations are independent of SLE-specific changes in accumulated disease damage and disease activity over time.

\section{METHODS}

\section{Study design, population and data sources}

We used data from the ongoing GOAL cohort study of patients with SLE in metropolitan Atlanta, Georgia. GOAL recruitment and data collection details have been published previously. ${ }^{26}$ Briefly, participants of the GOAL study were recruited primarily from the existing Georgia Lupus Registry, a population-based registry funded by the Centers for Disease Control and Prevention, in order to estimate the incidence and prevalence of SLE in metropolitan Atlanta. ${ }^{27}$ Patients not included in the registry but who were receiving SLE treatment at Emory University, at Grady Memorial Hospital (safety net hospital in Atlanta) or from community rheumatologists in metropolitan Atlanta at the time of study recruitment were additionally recruited to further enrich this population-based cohort. All participants were recruited by mail, by telephone and in person, and assessments have been performed annually since Wave 1 (baseline; September 2011-September 2012). A total of 850 adult participants (aged $\geq 18$ years) with a documented diagnosis of SLE (more than four revised American College of Rheumatology (ACR) criteria $^{28}$ or three ACR criteria plus a diagnosis of SLE by the attending board-certified rheumatologist) were included in Wave 1.

We used a cross-sectional design to describe the association of age at survey with HRQOL reported during a single wave (Wave 3; September 2013-September 2014). A total of 714 adult patients with SLE with known age (aged $\geq 20$ years at Wave 3 ) participated in Wave 3 of GOAL. For analyses, patients were excluded if they were missing HRQOL summary scores $(n=11)$ or any other covariates $(n=19)$, leaving 684 patients in the final models for summary scores. The Emory University Institutional Review Board, Grady Health System Research Oversight Committee and Georgia Department of Public Health Institutional Review Board approved the GOAL study protocol. All GOAL participants provided informed consent.

\section{Study variables}

Age at survey

Self-reported age at survey, which served as the exposure of interest, was grouped into categories of 20-39 (young), 40-59 (middle-aged) and $\geq 60$ (oldest) years for analyses, to estimate associations of HRQOL with different phases of the adult lifespan. ${ }^{29}$ Age at survey was also examined as a continuous exposure in sensitivity analyses (see below).

\section{HRQOL}

HRQOL was obtained from the self-administered SF-12 questionnaire, ${ }^{30}$ which is a validated 12-item version of the SF-36 questionnaire ${ }^{31}{ }^{32}$ recommended for use in SLE. ${ }^{14}$ Overall summary HRQOL scores (mental component summary (MCS) and physical component summary (PCS) scores; scale, 0-100, with higher scores representing better HRQOL, and 50 representing the average score for $45-54$ year olds in the general US population ${ }^{33}$ ) were calculated based on the responses to the 12 items $^{33}$ and served as the primary outcomes. Norm-based scoring of individual domain scores (physical functioning, role physical, bodily pain, general health, vitality, social functioning, role emotional and mental health) was used, such that the scales and interpretation of domain scores were the same as those for MCS and PCS, and the domain scores can be meaningfully compared. ${ }^{34}$

\section{SLE-related organ damage and activity}

SLE-related organ damage was assessed via the Brief Index of Lupus Damage (BILD) ${ }^{35}$ (range, 0-30, with higher scores indicating greater levels of damage); the 
self-administered BILD was further validated in GOAL. ${ }^{36}$ Current SLE activity was assessed via the Systemic Lupus Activity Questionnaire (SLAQ) ${ }^{37}$ (range, 0-44, with higher scores indicating greater SLE-related disease activity.

\section{Other variables}

Age at SLE onset, sex, race, ethnicity, body mass index (BMI), education, employment status, income and marital status were self-reported. SLE duration was calculated as the number of years between age at SLE onset and age at survey. Because older adults with SLE could have developed SLE as a child, as a young adult or as an older adult, we also categorised age at onset as paediatric ( $<18$ years), early adult (18-49 years) and late adult ( $\geq 50$ years) onset, as in prior studies. ${ }^{38}$ Emotional support was determined by the survey item 'How often do you get the emotional support you need?' and categorised as always/usually versus sometimes/rarely/never. Renal involvement in SLE was determined by whether renal ACR criteria $^{28}$ were met in the diagnosis of SLE. Impact of SLE was assessed via the Lupus Impact Tracker (LIT) ${ }^{39}$ instrument, which has scores scaled to $0-100$, with higher scores indicating greater impact of SLE. The presence of depressive symptoms was assessed via the nine-item Patient Health Questionnaire (PHQ-9) depression severity screener. ${ }^{40}$ PHQ-9 scores (range 0-27, with higher scores indicating more severe depression) were categorised as 5 or more (mild to severe depressive symptoms) versus 0-4 (none or minimal depressive symptoms).

\section{Statistical analysis}

Participant characteristics, including sociodemographic and clinical factors, were summarised overall and by age group. HRQOL scores were also summarised overall and by age group. Slopes $(\beta s)$ and $95 \%$ CIs for the associations between age group and HRQOL scores were estimated with multivariable linear regression models. Adjustment for a priori confounders sex and race (categorised as African-American vs not African-American) and for potential mediators between age and HRQOL (employment, marital status, emotional support and SLE duration) was performed; adjustment for SLE duration alone was also performed. Because the associations of SLE-related damage and SLE activity with age may differ in direction, the effects of further adjustment for damage (BILD score), activity (SLAQ score) and both were examined in this fully adjusted model, to explore the separate and combined influence of each on the association of age with HRQOL. In sensitivity analyses, we examined the effects of: (i) further adjustment for BMI, depressive symptoms and LIT score, which were excluded from main models because they are likely on the causal pathways between BILD, SLAQ and HRQOL; (ii) further adjustment for income, which were excluded from the main models due to missing data and likelihood of being on the pathway from employment and marital status to HRQOL; (iii) further adjustment for renal involvement in SLE, to account for the lack of renal components in the SLAQ score; (iv) using continuous versus categorical age, to address whether age cut-offs mask linear effects of age on HRQOL and (v) the addition of an age-squared term to the continuous age models (to assess whether the effects of age on HRQOL were potentially continuous but non-linear). Stata V.13 (StataCorp, College Station, Texas, USA) was used for all analyses, and the threshold for statistical significance was set at $\alpha=0.05$.

\section{RESULTS}

\section{Characteristics of the SLE cohort}

Table 1 shows that $29.0 \%, 52.9 \%$ and $18.1 \%$ of GOAL participants included in our study were aged 20-39, 4059 and $\geq 60$ years, respectively, with the mean age being 47.8 years (range $20-88$ years). A total of $26(3.8 \%)$ and $4(0.6 \%)$ participants were $\geq 70$ and $\geq 80$ years, respectively. Overall, $5.6 \%$ of participants were male and $78.5 \%$ were African-American, and there were no differences in sex or race by age group (table 1). Participants who were older were more likely to be or to have been married, to report always or usually having emotional support and to have higher annual income, compared with younger patients (table 1). While the oldest patients were most likely to report being unemployed (primarily due to retirement), $35.9 \%, 44.5 \%$ and $21.8 \%$ of young, middle-aged and older participants, respectively, reported not working due to disability.

Older age at SLE onset was seen among older participants, with mean ages of SLE onset of 21.8 versus 45.3 for the youngest versus oldest age groups (table 1). About one-third of patients aged $\geq 60$ years had late-onset SLE (table 1). BMI and BILD scores were higher with older age, whereas PHQ-9 and LIT scores were lower with older age; SLAQ scores were highest in the middle-age, but scores were not statistically significantly different across age groups (table 1 ).

In a comparison of participants included in the analysis $(\mathrm{n}=684)$ and participants excluded from the analysis due to missing data on HRQOL scores or covariates $(\mathrm{n}=30 ; 4.2 \%), 40.0 \%$ of those excluded were $\geq 60$ years old, versus $18.1 \%$ in the included cohort $(p<0.001)$. Related, mean SLE duration was longer (19.4 vs 15.4 years; $\mathrm{p}=0.03$ ) among excluded versus included participants. Other characteristics that differed by excluded versus included status were: male sex $(23.3 \%$ vs $5.6 \%$; $\mathrm{p}<0.001$ ), BMI (26.2 vs $\left.29.3 \mathrm{~kg} / \mathrm{m}^{2} ; \mathrm{p}=0.04\right)$ and education (13.2 vs 14.6 years; $\mathrm{p}=0.01$ ). No other characteristics listed in table 1, including BILD and SLAQ scores, differed by exclusion status.

\section{Association of HRQOL with age in a cohort of patients with} SLE

The SF-12 norm-based scores were $<50$ for all HRQOL domains, overall and across age categories (table 2). 
Table 1 Characteristics of the Georgians Organized Against Lupus cohort of patients with SLE in September 2013-November 2014, overall and by categorised age at survey

\begin{tabular}{|c|c|c|c|c|c|c|}
\hline \multirow[b]{2}{*}{ Characteristic } & \multirow[b]{2}{*}{$\mathbf{N}$} & \multirow[b]{2}{*}{ Overall } & \multicolumn{3}{|c|}{ Age at survey, years } & \multirow[b]{2}{*}{ p Value* } \\
\hline & & & $\begin{array}{l}20-39 \\
N=198(29.0 \%)\end{array}$ & $\begin{array}{l}40-59 \\
N=362(52.9 \%)\end{array}$ & $\begin{array}{l}\geq 60 \\
N=124(18.1 \%)\end{array}$ & \\
\hline \multicolumn{7}{|l|}{ Sociodemographic } \\
\hline Mean (SD) age at survey & 684 & $47.8(13.0)$ & $32.3(5.1)$ & $49.8(5.7)$ & $66.9(5.7)$ & $<0.001$ \\
\hline$\%$ Male & 684 & $5.6 \%$ & $5.6 \%$ & $5.8 \%$ & $4.8 \%$ & 0.92 \\
\hline Race, \% & 684 & & & & & 0.16 \\
\hline White & & $19.6 \%$ & $19.2 \%$ & $18.0 \%$ & $25.0 \%$ & \\
\hline African-American & & $78.5 \%$ & $77.3 \%$ & $81.0 \%$ & $74.2 \%$ & \\
\hline Other & & $1.9 \%$ & $3.5 \%$ & $1.4 \%$ & $0.8 \%$ & \\
\hline$\%$ Hispanic/Latino & 680 & $5.0 \%$ & $7.1 \%$ & $4.7 \%$ & $2.4 \%$ & 0.16 \\
\hline Marital status, \% & 684 & & & & & $<0.001$ \\
\hline Never married & & $32.5 \%$ & $58.1 \%$ & $26.26 \%$ & $9.7 \%$ & \\
\hline Married & & $32.6 \%$ & $18.2 \%$ & $37.1 \%$ & $42.7 \%$ & \\
\hline Separated, divorced, widowed & & $34.9 \%$ & $23.7 \%$ & $36.7 \%$ & $47.6 \%$ & \\
\hline Mean (SD) years of education & 673 & $14.6(3.1)$ & $14.6(2.9)$ & $14.6(3.0)$ & $14.9(3.5)$ & 0.64 \\
\hline Employment, \% & 684 & & & & & $<0.001$ \\
\hline Employed & & $37.3 \%$ & $45.0 \%$ & $38.7 \%$ & $21.0 \%$ & \\
\hline Not employed $\dagger$ & & $24.9 \%$ & $19.2 \%$ & $16.9 \%$ & $57.3 \%$ & \\
\hline Disabled & & $37.9 \%$ & $35.9 \%$ & $44.5 \%$ & $21.8 \%$ & \\
\hline Income, \% & 630 & & & & & $<0.001$ \\
\hline$<$ US\$20000 & & $41.1 \%$ & $47.6 \%$ & $42.9 \%$ & $24.6 \%$ & \\
\hline US\$20 000-\$49999 & & $27.0 \%$ & $30.2 \%$ & $22.7 \%$ & $34.6 \%$ & \\
\hline$\geq$ US\$50 000 & & $31.9 \%$ & $22.2 \%$ & $34.4 \%$ & $40.9 \%$ & \\
\hline $\begin{array}{l}\text { \% Always/usually have } \\
\text { emotional support }\end{array}$ & 684 & $56.7 \%$ & $57.6 \%$ & $53.3 \%$ & $65.3 \%$ & 0.06 \\
\hline \multicolumn{7}{|l|}{ Clinical } \\
\hline Mean (SD) age at onset & 684 & 32.4 (12.2) & $21.8(6.1)$ & $33.8(9.5)$ & $45.3(11.8)$ & $<0.001$ \\
\hline Age at onset, \% & 684 & & & & & $<0.001$ \\
\hline Paediatric (<18 years) & & $10.5 \%$ & $26.3 \%$ & $4.7 \%$ & $2.4 \%$ & \\
\hline Early adult (18-49 years) & & $81.0 \%$ & $73.7 \%$ & $91.7 \%$ & $61.3 \%$ & \\
\hline Late adult $(\geq 50$ years) & & $8.5 \%$ & $0.0 \%$ & $3.6 \%$ & $36.3 \%$ & \\
\hline Mean (SD) duration of SLE, years & 684 & $15.4(9.6)$ & $10.5(5.9)$ & $15.9(9.3)$ & $21.6(11.3)$ & $<0.001$ \\
\hline$\%$ SLE onset within past 10 years & 684 & $33.6 \%$ & $49.5 \%$ & $31.2 \%$ & $15.3 \%$ & $<0.001$ \\
\hline Mean (SD) BMI & 644 & $29.3(7.8)$ & $28.1(7.7)$ & $30.0(8.1)$ & $29.3(6.8)$ & 0.03 \\
\hline Renal involvementł, \% & 633 & $30.2 \%$ & $41.5 \%$ & $27.7 \%$ & $21.3 \%$ & $<0.001$ \\
\hline Median (IQR) PHQ-9 score & 683 & $7(3-12)$ & $7(3-12)$ & $8(4-13)$ & $6(2-10)$ & 0.004 \\
\hline Median (IQR) BILD score & 684 & $3(1-5)$ & $2(1-3)$ & $3(1-5)$ & $4(2-5)$ & $<0.001$ \\
\hline Median (IQR) SLAQ score & 684 & $15(9-23)$ & $15(9-23)$ & $17(10-24)$ & $15(8-20)$ & 0.22 \\
\hline Mean (SD) LIT score & 682 & $41.8(24.1)$ & $40.9(24.0)$ & $43.9(24.4)$ & $37.1(22.6)$ & 0.02 \\
\hline $\begin{array}{l}{ }^{\star} \text { By } \chi^{2} \text {, Fisher's exact, analysis of varia } \\
\text { †Includes retired, student and homema } \\
\text { †From American College of Rheumatol } \\
\text { BILD, Brief Index of Lupus Damage; B }\end{array}$ & e or $\mathrm{nc}$ & $\begin{array}{l}\text { parametric eq } \\
\text { ion. } \\
\text { stic criteria. } \\
\text { ass index; LIT, }\end{array}$ & lity-of-medians tes & $\begin{array}{l}\text { s appropriate. } \\
\text { PHQ-9, nine-iten }\end{array}$ & ent Health Quest & aire; \\
\hline
\end{tabular}

Overall, scores reflecting physical aspects of HRQOL were lower in older age groups: PCS scores were 41.8, 38.7 and 37.4 among the young, middle-age and oldest age groups, respectively, and patterns were similar for the physical functioning, role physical and bodily pain scores (table 2). In contrast, general health, vitality, social functioning and role emotional scores were similar across age groups, and MCS and mental health scores were highest in the oldest group, although the differences were not statistically significant (table 2). A spider plot by age group (figure 1) demonstrates that the youngest age group had the highest mean scores related to physical aspects of HRQOL, but lower scores related to mental aspects of HRQOL, relative to the oldest patients. The oldest patients had the lowest and highest scores on physical and mental aspects of HRQOL, respectively; and the middle-aged patients had the lowest MCS and mental health scores (figure 1).

In crude regression analyses of HRQOL scores by categorised age, PCS scores were lower among those aged $40-59$ and $\geq 60$ years (by 3.3 and 4.1 points, on average), compared with those aged 20-39 years (table 3). Adjustment for SLE duration alone generally resulted in very similar results (table 3). Adjustment for sex, race, 
Table 2 Health-related quality of life scores among the Georgians Organized Against Lupus cohort of patients with systemic lupus erythematosus in September 2013-November 2014, overall and by categorised age at survey

\begin{tabular}{|c|c|c|c|c|c|c|c|c|}
\hline \multirow[b]{3}{*}{ SF-12 domain } & \multirow[b]{3}{*}{$\mathbf{N}$} & \multicolumn{4}{|c|}{ Mean (SD) norm-based SF-12 scores*: } & \multirow[b]{3}{*}{ p Valuet } & \multirow[b]{3}{*}{$\rho$ value‡ } & \multirow[b]{3}{*}{ p Valueł } \\
\hline & & \multirow[b]{2}{*}{ Overall } & \multicolumn{3}{|c|}{ Age at survey } & & & \\
\hline & & & $\begin{array}{l}20-39 \\
\text { years }\end{array}$ & $\begin{array}{l}40-59 \\
\text { years }\end{array}$ & $\geq 60$ years & & & \\
\hline $\begin{array}{l}\text { Physical component } \\
\text { summary }\end{array}$ & 703 & 39.3 (10.9) & $41.8(11.7)$ & $38.7(10.5)$ & $37.4(10.0)$ & $<0.001$ & -0.18 & $<0.001$ \\
\hline Physical functioning & 703 & $39.6(11.3)$ & $41.9(11.5)$ & $39.1(11.2)$ & $37.6(11.0)$ & $<0.001$ & -0.17 & $<0.001$ \\
\hline Role physical & 702 & 39.7 (10.9) & $41.7(10.9)$ & $39.0(10.9)$ & $38.9(10.5)$ & 0.01 & -0.10 & 0.01 \\
\hline Bodily pain & 693 & $39.4(11.4)$ & $40.7(11.6)$ & $38.9(11.5)$ & $38.6(10.6)$ & 0.15 & -0.11 & 0.004 \\
\hline General health & 698 & $41.8(10.7)$ & $43.5(11.3)$ & $40.9(10.4)$ & $41.9(10.2)$ & 0.02 & -0.08 & 0.03 \\
\hline Mental component summary & 703 & $44.3(11.4)$ & $44.2(11.7)$ & $43.8(11.4)$ & $46.1(11.2)$ & 0.14 & 0.06 & 0.09 \\
\hline Mental health & 703 & $45.1(10.9)$ & $45.1(11.3)$ & 44.5 (10.9) & $46.9(10.1)$ & 0.08 & 0.06 & 0.10 \\
\hline Role emotional & 700 & $40.2(13.4)$ & $41.1(13.6)$ & 39.4 (13.3) & 40.9 (13.3) & 0.30 & -0.01 & 0.85 \\
\hline Social functioning & 698 & $41.4(11.0)$ & $42.3(10.6)$ & $40.7(11.1)$ & $41.7(11.4)$ & 0.29 & -0.03 & 0.36 \\
\hline Vitality & 701 & $43.7(10.2)$ & $44.3(10.2)$ & $43.5(10.2)$ & $43.4(10.3)$ & 0.63 & -0.03 & 0.42 \\
\hline
\end{tabular}

employment, marital status, emotional support and SLE duration attenuated the associations, particularly for those aged 40-59 versus 20-39, but the associations remained negative and statistically significant. Further adjustment for BILD and SLAQ scores did not change the results substantially (table 3 ). A similar pattern was seen for the associations of physical functioning, role physical, bodily pain and general health subdomain scores with categorised age, but only the association of age with physical functioning remained statistically significant after adjustment (table 3 ).

In contrast, MCS scores did not differ for participants who were 40-59 and 20-39 years of age; those aged $>60$ years had higher MCS scores (by 2.1 points, on average) than those aged 20-39 years, but the difference

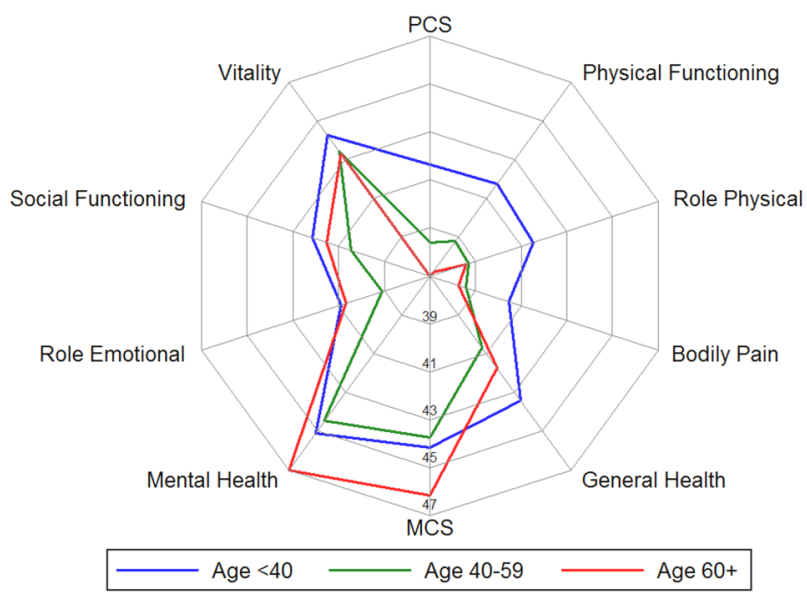

Figure 1 Overall summary and individual component health-related quality of life scores among patients with systemic lupus erythematosus by age group, in the Georgians Organized Against Lupus cohort, September 2013-November 2014. MCS, mental component summary; PCS, physical component summary. was not statistically significant (table 3). Adjustment for sex, race, employment, marital status, emotional support and SLE duration rendered the association between age $\geq 60$ versus 20-39 with MCS non-statistically significant (table 3). Further adjustment for SLE damage (BILD score) and SLE activity (SLAQ score) did not change the results. A nearly identical pattern was seen for the mental health subdomain score (table 3). Middle-aged (but not older) participants appeared to have lower $(0.9-1.6$ points) scores than younger patients on vitality, social functioning and role emotional subdomain scores in crude analyses, but these associations were not statistically significant and were rendered null by full adjustment (table 3).

\section{Sensitivity analyses}

Further adjustment for BMI, depression and lupus impact score generally did not substantially change the patterns seen in the primary analyses, although there was a suggestion of slightly stronger associations after this adjustment among those aged $\geq 60$ years (see online supplementary table S1). Adjustment for income showed similar results to those in the primary analyses (see online supplementary table S1). Adjustment for renal involvement in SLE resulted in slightly higher magnitude of negative associations of age with physical aspects of HRQOL (see online supplementary table S1). Similar to the results with categorised age, lower PCS and physical subdomain scores remained statistically significantly associated with older, continuous age after adjustment, whereas MCS and mental subdomain scores were generally not associated with continuous age (see online supplementary table S2). Age-squared (in addition to continuous age) was only statistically significantly (and positively) associated with MCS and mental health scores in these continuous models, but these associations were not robust to adjustment (data not shown). 
Table 3 Overall associations of categorised age at survey with summary health-related quality of life scores among patients with SLE in the Georgians Organized Against Lupus cohort, September 2013-November 2014

\begin{tabular}{|c|c|c|}
\hline \multirow[b]{2}{*}{ Domain/model } & \multicolumn{2}{|c|}{ Difference in score $(95 \% \mathrm{Cl})$, compared with age $20-39$ years } \\
\hline & Age 40-59 years & Age $\geq 60$ years \\
\hline \multicolumn{3}{|l|}{ Physical component summary $(\mathrm{N}=684)$} \\
\hline Crude & $-3.26(-5.12$ to -1.39$)$ & $-4.13(-6.55$ to -1.71$)$ \\
\hline Adjusted for SLE duration only & $-3.28(-5.21$ to -1.35$)$ & $-4.18(-6.80$ to -1.56$)$ \\
\hline Multivariable-adjusted ${ }^{\star}$ & $-2.53(-4.38$ to -0.67$)$ & $-3.57(-6.19$ to -0.96$)$ \\
\hline Multivariable+BILD score & $-2.10(-3.93$ to -0.28$)$ & $-3.43(-5.99$ to -0.87$)$ \\
\hline Multivariable+SLAQ score & $-2.15(-3.87$ to -0.43$)$ & $-3.13(-5.55$ to -0.71$)$ \\
\hline Multivariable+BILD and SLAQ score & $-1.85(-3.55$ to -0.15$)$ & $-3.05(-5.43$ to -0.66$)$ \\
\hline \multicolumn{3}{|l|}{ Physical functioning $(\mathrm{N}=684)$} \\
\hline Crude & $-3.04(-4.99$ to -1.09$)$ & $-3.97(-6.49$ to -1.44$)$ \\
\hline Adjusted for SLE duration only & $-3.09(-5.11$ to -1.07$)$ & $-4.07(-6.80$ to -1.33$)$ \\
\hline Multivariable-adjusted ${ }^{\star}$ & $-2.12(-4.04$ to -0.19$)$ & $-3.42(-6.13$ to -0.72$)$ \\
\hline Multivariable+BILD score & $-1.76(-3.67$ to 0.14$)$ & $-3.30(-5.97$ to -0.63$)$ \\
\hline Multivariable+SLAQ score & $-1.76(-3.57$ to 0.05$)$ & $-3.01(-5.55$ to -0.47$)$ \\
\hline Multivariable+BILD and SLAQ score & $-1.52(-3.32$ to 0.27$)$ & $-2.94(-5.46$ to -0.42$)$ \\
\hline \multicolumn{3}{|l|}{ Role physical $(\mathrm{N}=683)$} \\
\hline Crude & $-2.83(-4.71$ to -0.95$)$ & $-2.57(-5.00$ to -0.13$)$ \\
\hline Adjusted for SLE duration only & $-3.09(-5.04$ to -1.15$)$ & $-3.10(-5.74$ to -0.47$)$ \\
\hline Multivariable-adjusted ${ }^{\star}$ & $-2.05(-3.90$ to -0.19$)$ & $-2.58(-5.18$ to 0.02$)$ \\
\hline Multivariable+BILD score & $-1.70(-3.53$ to 0.14$)$ & $-2.46(-5.03$ to 0.11$)$ \\
\hline Multivariable+SLAQ score & $-1.67(-3.38$ to 0.04$)$ & $-2.13(-4.53$ to 0.27$)$ \\
\hline Multivariable+BILD and SLAQ score & $-1.45(-3.15$ to 0.25$)$ & $-2.07(-4.45$ to 0.31$)$ \\
\hline \multicolumn{3}{|l|}{ Bodily pain $(\mathrm{N}=674)$} \\
\hline Crude & $-1.87(-3.85$ to 0.11$)$ & $-1.75(-4.33$ to 0.82$)$ \\
\hline Adjusted for SLE duration only & $-1.88(-3.93$ to 0.17$)$ & $-1.77(-4.57$ to 1.02$)$ \\
\hline Multivariable-adjusted ${ }^{\star}$ & $-0.88(-2.83$ to 1.07$)$ & $-1.70(-4.45$ to 1.05$)$ \\
\hline Multivariable+BILD score & $-0.52(-2.46$ to 1.41$)$ & $-1.61(-4.32$ to 1.10$)$ \\
\hline Multivariable+SLAQ score & $-0.34(-2.07$ to 1.40$)$ & $-1.15(-3.60$ to 1.29$)$ \\
\hline Multivariable+BILD and SLAQ score & $-0.15(-1.88$ to 1.58$)$ & $-1.12(-3.55$ to 1.31$)$ \\
\hline \multicolumn{3}{|l|}{ General health $(\mathrm{N}=679)$} \\
\hline Crude & $-2.65(-4.50$ to -0.80$)$ & $-1.56(-3.97$ to 0.85$)$ \\
\hline Adjusted for SLE duration only & $-2.80(-4.72$ to -0.89$)$ & $-1.87(-4.48$ to 0.74$)$ \\
\hline Multivariable-adjusted ${ }^{\star}$ & $-2.14(-4.03$ to -0.25$)$ & $-1.63(-4.29$ to 1.03$)$ \\
\hline Multivariable+BILD score & $-1.82(-3.69$ to 0.06$)$ & $-1.53(-4.16$ to 1.10$)$ \\
\hline Multivariable+SLAQ score & $-1.71(-3.44$ to 0.01$)$ & $-1.15(-3.58$ to 1.27$)$ \\
\hline Multivariable+BILD and SLAQ score & $-1.52(-3.24$ to 0.20$)$ & $-1.11(-3.52$ to 1.31$)$ \\
\hline \multicolumn{3}{|l|}{ Mental component summary $(\mathrm{N}=684)$} \\
\hline Crude & $-0.33(-2.31$ to 1.65$)$ & $2.10(-0.46$ to 4.67$)$ \\
\hline Adjusted for SLE duration only & $-0.73(-2.77$ to 1.32$)$ & $1.29(-1.48$ to 4.07$)$ \\
\hline Multivariable-adjusted* & $0.47(-1.46$ to 2.41$)$ & $1.20(-1.52$ to 3.92$)$ \\
\hline Multivariable+BILD score & $0.49(-1.45$ to 2.43$)$ & $1.20(-1.51$ to 3.92$)$ \\
\hline Multivariable+SLAQ score & $0.86(-0.94$ to 2.65$)$ & $1.65(-0.87$ to 4.17$)$ \\
\hline Multivariable+BILD and SLAQ score & $0.76(-1.04$ to 2.56$)$ & $1.62(-0.90$ to 4.15$)$ \\
\hline \multicolumn{3}{|l|}{ Mental health $(\mathrm{N}=684)$} \\
\hline Crude & $-0.41(-2.29$ to 1.47$)$ & $2.04(-0.39$ to 4.48$)$ \\
\hline Adjusted for SLE duration only & $-0.76(-2.70$ to 1.18$)$ & $1.32(-1.31$ to 3.96$)$ \\
\hline Multivariable-adjusted ${ }^{\star}$ & $0.50(-1.35$ to 2.35$)$ & $1.36(-1.25$ to 3.96$)$ \\
\hline Multivariable+BILD score & $0.52(-1.34$ to 2.38$)$ & $1.36(-1.24$ to 3.97$)$ \\
\hline Multivariable+SLAQ score & $0.87(-0.84$ to 2.59$)$ & $1.79(-0.62$ to 4.20$)$ \\
\hline Multivariable+BILD and SLAQ score & $0.79(-0.93$ to 2.51$)$ & $1.77(-0.64$ to 4.18$)$ \\
\hline \multicolumn{3}{|l|}{ Role emotional $(\mathrm{N}=681)$} \\
\hline Crude & $-1.62(-3.94$ to 0.71$)$ & $0.14(-2.87$ to 3.16$)$ \\
\hline Adjusted for SLE duration only & $-1.94(-4.35$ to 0.46$)$ & $-0.52(-3.79$ to 2.74$)$ \\
\hline Multivariable-adjusted* & $-0.86(-3.11$ to 1.40$)$ & $-0.85(-4.01$ to 2.32$)$ \\
\hline Multivariable+BILD score & $-0.69(-2.95$ to 1.57$)$ & $-0.79(-3.95$ to 2.37$)$ \\
\hline Multivariable+SLAQ score & $-0.42(-2.53$ to 1.69$)$ & $-0.34(-3.30$ to 2.63$)$ \\
\hline Multivariable+BILD and SLAQ score & $-0.38(-2.50$ to 1.74$)$ & $-0.33(-3.30$ to 2.64$)$ \\
\hline
\end{tabular}




\begin{tabular}{|c|c|c|}
\hline \multirow[b]{2}{*}{ Domain/model } & \multicolumn{2}{|c|}{ Difference in score $(95 \% \mathrm{Cl})$, compared with age $20-39$ years } \\
\hline & Age $40-59$ years & Age $\geq 60$ years \\
\hline \multicolumn{3}{|l|}{ Social functioning $(\mathrm{N}=680)$} \\
\hline Crude & $-1.72(-3.64$ to 0.21$)$ & $-0.42(-2.91$ to 2.06$)$ \\
\hline Adjusted for SLE duration only & $-1.91(-3.90$ to 0.08$)$ & $-0.82(-3.52$ to 1.88$)$ \\
\hline Multivariable-adjusted* & $-0.71(-2.62$ to 1.21$)$ & $-0.50(-3.19$ to 2.18$)$ \\
\hline Multivariable+BILD score & $-0.47(-2.38$ to 1.44$)$ & $-0.41(-3.08$ to 2.26$)$ \\
\hline Multivariable+SLAQ score & $-0.26(-1.99$ to 1.46$)$ & $0.01(-2.41$ to 2.43$)$ \\
\hline Multivariable+BILD and SLAQ score & $-0.16(-1.89$ to 1.57$)$ & $0.04(-2.37$ to 2.46$)$ \\
\hline \multicolumn{3}{|l|}{ Vitality $(\mathrm{N}=682)$} \\
\hline Crude & $-0.94(-2.72$ to 0.83$)$ & $-0.86(-3.16$ to 1.43$)$ \\
\hline Adjusted for SLE duration only & $-1.33(-3.16$ to 0.50$)$ & $-1.66(-4.15$ to 0.82$)$ \\
\hline Multivariable-adjusted* & $-0.51(-2.34$ to 1.33$)$ & $-1.25(-3.83$ to 1.33$)$ \\
\hline Multivariable+BILD score & $-0.41(-2.25$ to 1.43$)$ & $-1.22(-3.79$ to 1.36$)$ \\
\hline Multivariable+SLAQ score & $-0.19(-1.92$ to 1.54$)$ & $-0.84(-3.27$ to 1.59$)$ \\
\hline Multivariable+BILD and SLAQ score & $-0.18(-1.92$ to 1.55$)$ & $-0.84(-3.27$ to 1.59$)$ \\
\hline
\end{tabular}

\section{DISCUSSION}

In this cross-sectional study of a cohort of patients with SLE of all ages, we examined the associations of age with HRQOL and the contributions of cumulative disease damage and disease activity to these associations. We found that, on average, patients with SLE in the middle-aged and older versus younger age groups had lower scores on physical aspects of HRQOL. However, older patients had similar or even slightly higher scores on mental aspects of HRQOL, relative to both young and middle-aged patients. These associations were generally robust to adjustment with potential confounders and independent of the effect of both cumulative SLE-related damage and current SLE activity.

Regardless of age or HRQOL domain, scores in this predominantly African-American cohort of patients with SLE were low, with all HRQOL norm-based scores being $<50$, indicating poorer health in SLE than in general population. This observation is consistent with prior studies, showing that HRQOL is worse among patients with SLE than similarly aged counterparts with other chronic conditions, including hypertension, diabetes and myocardial infarction, across domains of HRQOL. ${ }^{3}$ The patients with in our study actually had HRQOL scores similar to those of patients with end-stage renal disease treated with dialysis, for example, the PCS and MCS scores reported for US patients on dialysis are 33.1 and $46.6,{ }^{41}$ respectively, compared with 39.3 and 44.3 in our cohort.

Despite these generally low scores, there was variation in reported HRQOL scores by age group. The directions of the crude associations of HRQOL domains with older age were similar to those reported in the general population, in whom consistently lower physical HRQOL scores are seen for older versus younger individuals, but higher mental HRQOL scores are seen among older (and younger) versus middle-aged individuals. ${ }^{29}{ }^{42}$ With adjustment for confounders and mediators, only the negative association of older age with lower physical HRQOL remained statistically significant. To our knowledge, the only prior study to examine the association of categorised age with HRQOL showed that older $(\geq 65)$ versus younger $(<65)$ patients with rheumatic diseases including SLE had lower HRQOL across all domains. ${ }^{43}$ However, the study did not separate the middle-aged patients and did not examine the association specifically in patients with SLE, likely due to small numbers of patients with SLE at older ages. We were also somewhat limited in our ability to compare HRQOL in the oldest patients with our younger patients (given that $<4 \%$ and $<1 \%$ of the patients in our cohort were $\geq 70$ and $\geq 80$ years old). However, for SLE, being $>60$ years old may be reasonably considered 'older', given relatively recent increases in longevity, similar to the HIV population, where $\geq 50$ years is considered older. ${ }^{44}$

We also found that greater cumulative SLE-related damage was associated with older age but that SLE activity was similar across age groups. In a 2-year prospective study, Mok et $a l^{13}$ showed that disease damage but not disease activity was associated with lower HRQOL; however, we found that disease damage and disease activity had similar individual effects on the associations of age with HRQOL, after adjustment for other important factors, such as race, sex, employment and lupus duration. Furthermore, these effects were modest, with neither disease damage nor disease activity (or both in combination) explaining the observed associations of age with HRQOL in middle-aged or older versus younger patients with SLE. Interestingly, we found that the modest effects of disease damage and activity may 
have differed by age, with effects of these factors being stronger in the middle-aged patients: for example, compared with the model adjusted for all other confounding and mediating factors, further adjustment for BILD and SLAQ scores gave effect estimates that were reduced by $27 \%$ versus $11 \%$ in the middle-aged versus older adults. Thus, the contributions of SLE-related damage and activity to HRQOL may be less important to consider in older patients, who may benefit from a more innovative and patient-centred approach to their health and well-being.

Collectively, we found that associations of age with HRQOL among patients with SLE were not necessarily straightforward and, further, were not entirely explained by disease burden and activity in patients with SLE. These findings suggest that the effect of older age on HRQOL is mediated by non-disease factors, consistent with prior studies in both healthy individuals ${ }^{15}$ and individuals with renal insufficiency. ${ }^{16}$ Thus, in patients with SLE, a multidisciplinary, patient-centred approach, which emphasises syndromes analogous to geriatric syndromes $^{245}$ and includes assessment of physical, mental, emotional and social functioning across all life stages, ${ }^{46}$ may be preferable to the traditional disease-centred approach, which primarily emphasises the treatment of disease-related signs and symptoms. In the heterogeneous population of older patients with SLE, which includes survivors of early-onset SLE and patients with relatively recent late-onset SLE, who may have different care needs, this approach may be particularly important. In the clinical setting, more patient-centred, goal-oriented care could lead to better, more appropriate shared decision-making and a focus on the outcomes most important to individual patients. ${ }^{48}$ Furthermore, future health services research that includes comprehensive geriatric assessment across patients with SLE of all ages, including assessment of HRQOL and other important syndromes such as impaired physical and cognitive function and frailty, has the potential to inform both clinical care and successful ageing in setting of SLE. $^{49}$

There are several limitations of this study that deserve mention. First, this is a cross-sectional study, which limits causal inference. Additionally, the lack of long-term follow-up data means that we do not know individual trajectories of HRQOL over time. ${ }^{22}{ }^{50}$ Thus, we cannot rule out survivor effects with age. Exclusions due to missing data may have led to selection bias, given observed differences between excluded and included participants; however, missingness was minimal $(<5 \%)$. As with all observational studies, it is possible that we have not accounted for unknown or unmeasured confounders or mediators. Misclassification is also possible; for example, disease activity may be underestimated with SLAQ, which does not include items related to renal disease. While we adjusted for renal involvement in SLE in sensitivity analyses, renal activity at the time of survey is unknown. Finally, generalisability of the results may be limited due to the single location and potential healthy cohort effects. However, the study also has several strengths, including relatively large sample sizes within older age groups; a population-based sample of patients with SLE and adequate representation of African-American patients, who are at disproportionate risk of SLE and poor outcomes in SLE, in each age group.

HRQOL is low in SLE, regardless of age. Further, older age is associated with lower physical, but not mental, HRQOL among patients with SLE. These associations are independent of accumulated SLE damage and current SLE activity, suggesting that studies of the associations between other important geriatric outcomes in addition to HRQOL in the setting of SLE are warranted. Furthermore, the results highlight the need to establish patient-centred clinical strategies to prepare for an ageing SLE population.

\section{Author affiliations}

${ }^{1}$ Division of Renal Medicine, Emory University, Atlanta, Georgia, USA

${ }^{2}$ Division of Geriatrics and General Medicine, Emory University, Atlanta,

Georgia, USA

${ }^{3}$ Division of Rheumatology, Department of Medicine, Emory University, Atlanta, Georgia, USA

${ }^{4}$ Birmingham/Atlanta VA Geriatrics Research and Clinical Center, Atlanta, Georgia, USA

Acknowledgements The GOAL study was supported by Human Genome Science and GlaxoSmithKline (GH0-11-3366). SSL and CD are supported by the NIH (R01AR065493) and the CDC (U01DP005119).

Contributors All contributors meet the criteria for authorship and approved the submitted version of the manuscript

Funding GlaxoSmithKline (GH0-11-3366), Centers for Disease Control and Prevention (U01DP005119), National Institute of Arthritis and Musculoskeletal and Skin Diseases (R01AR065493).

Competing interests None declared.

Patient consent Obtained.

Ethics approval Emory University Institutional Review Board.

Provenance and peer review Not commissioned; externally peer reviewed.

Data sharing statement GOAL is an ongoing cohort study, and data are not available.

Open Access This is an Open Access article distributed in accordance with the Creative Commons Attribution Non Commercial (CC BY-NC 4.0) license, which permits others to distribute, remix, adapt, build upon this work noncommercially, and license their derivative works on different terms, provided the original work is properly cited and the use is non-commercial. See: http:// creativecommons.org/licenses/by-nc/4.0/

\section{REFERENCES}

1. Brunsting LA. Disseminated (systemic) lupus erythematosus. Proc Mayo Clinic 1952;27:410-12.

2. Inouye SK, Studenski S, Tinetti ME, et al. Geriatric syndromes: clinical, research, and policy implications of a core geriatric concept. J Am Geriatr Soc 2007;55:780-91.

3. Jolly M. How does quality of life of patients with systemic lupus erythematosus compare with that of other common chronic illnesses? J Rheumatol 2005;32:1706-8.

4. McElhone K, Abbott J, Teh LS. A review of health related quality of life in systemic lupus erythematosus. Lupus 2006;15:633-43.

5. Lim SS, Drenkard C. Epidemiology of lupus: an update. Curr Opin Rheumatol 2015;27:427-32. 
6. Howden LM, Meyer JA. Age and Sex Composition: 2010. 2010 Census Briefs: U.S. Department of Commerce. 2011. http://www. census.gov/prod/cen2010/briefs/c2010br-03.pdf

7. Boddaert J, Huong DL, Amoura Z, et al. Late-onset systemic lupus erythematosus: a personal series of 47 patients and pooled analysis of 714 cases in the literature. Medicine (Baltimore) 2004:83:348-59.

8. Kasitanon N, Magder LS, Petri M. Predictors of survival in systemic lupus erythematosus. Medicine (Baltimore) 2006;85:147-56.

9. Khanna S, Pal H, Pandey RM, et al. The relationship between disease activity and quality of life in systemic lupus erythematosus. Rheumatology (Oxford) 2004;43:1536-40.

10. Stoll T, Gordon C, Seifert B, et al. Consistency and validity of patient administered assessment of quality of life by the MOS SF-36; its association with disease activity and damage in patients with systemic lupus erythematosus. J Rheumatol 1997;24:1608-14.

11. Hanly JG. Disease activity, cumulative damage and quality of life in systematic lupus erythematosus: results of a cross-sectional study. Lupus 1997;6:243-7.

12. Meacock R, Dale N, Harrison MJ. The humanistic and economic burden of systemic lupus erythematosus: a systematic review. Pharmacoeconomics 2013;31:49-61.

13. Mok CC, Ho LY, Cheung MY, et al. Effect of disease activity and damage on quality of life in patients with systemic lupus erythematosus: a 2-year prospective study. Scand $J$ Rheumatol 2009;38:121-7.

14. Gladman D, Urowitz M, Fortin P, et al. Systemic Lupus International Collaborating Clinics conference on assessment of lupus flare and quality of life measures in SLE. Systemic Lupus International Collaborating Clinics Group. J Rheumatol 1996;23:1953-5.

15. Covinsky KE, Wu AW, Landefeld CS, et al. Health status versus quality of life in older patients: does the distinction matter? Am J Med 1999;106:435-40.

16. Chow FYF, Briganti EM, Kerr PG, et al. Health-related quality of life in Australian adults with renal insufficiency: a population-based study. Am J Kidney Dis 2003;41:596-604.

17. Rivest C, Lew RA, Welsing PM, et al. Association between clinical factors, socioeconomic status, and organ damage in recent onset systemic lupus erythematosus. J Rheumatol 2000;27:680-4.

18. Yazdany J, Yelin EH, Panopalis P, et al. Validation of the systemic lupus erythematosus activity questionnaire in a large observational cohort. Arthritis Rheum 2008;59:136-43.

19. Alarcon GS, McGwin G Jr, Uribe A, et al. Systemic lupus erythematosus in a multiethnic lupus cohort (LUMINA). XVII. Predictors of self-reported health-related quality of life early in the disease course. Arthritis Rheum 2004;51:465-74.

20. Urowitz M, Gladman DD, Ibañez D, et al. Changes in quality of life in the first 5 years of disease in a multicenter cohort of patients with systemic lupus erythematosus. Arthritis Care Res (Hoboken) 2014:66:1374-9.

21. Urowitz MB, Gladman DD, Ibañez D, et al. Evolution of disease burden over five years in a multicenter inception systemic lupus erythematosus cohort. Arthritis Care Res (Hoboken) 2012;64:132-7.

22. Zhang J, González LA, Roseman JM, et al. Predictors of the rate of change in disease activity over time in LUMINA, a multiethnic US cohort of patients with systemic lupus erythematosus: LUMINA LXX. Lupus 2010;19:727-33.

23. Alarcon GS, Calvo-Alen J, McGwin G Jr, et al. Systemic lupus erythematosus in a multiethnic cohort: LUMINA XXXV. Predictive factors of high disease activity over time. Ann Rheum Dis 2006;65:1168-74.

24. Bruce IN, O'Keeffe AG, Farewell V, et al. Factors associated with damage accrual in patients with systemic lupus erythematosus: results from the Systemic Lupus International Collaborating Clinics (SLICC) Inception Cohort. Ann Rheum Dis 2015;74:1706-13.

25. Petri M, Purvey S, Fang $\mathrm{H}$, et al. Predictors of organ damage in systemic lupus erythematosus: the Hopkins Lupus Cohort. Arthritis Rheum 2012;64:4021-8.

26. Drenkard C, Rask KJ, Easley KA, et al. Primary preventive services in patients with systemic lupus erythematosus: study from a population-based sample in Southeast U.S. Semin Arthritis Rheum 2013;43:209-16.
27. Lim SS, Bayakly AR, Helmick CG, et al. The incidence and prevalence of systemic lupus erythematosus, 2002-2004: the Georgia Lupus Registry. Arthr Rheumatol (Hoboken, NJ) 2014:66:357-68.

28. Hochberg MC. Updating the American College of Rheumatology revised criteria for the classification of systemic lupus erythematosus. Arthritis Rheum 1997;40:1725.

29. Mishra GD, Hockey R, Dobson AJ. A comparison of SF-36 summary measures of physical and mental health for women across the life course. Qual Life Res 2014;23:1515-21.

30. Jenkinson $C$, Layte R, Jenkinson $\mathrm{D}$, et al. A shorter form health survey: can the SF-12 replicate results from the SF-36 in longitudinal studies? J Public Health Med 1997;19:179-86.

31. Ware JE Jr, Sherbourne CD. The MOS 36-item short-form health survey (SF-36). I. Conceptual framework and item selection. Med Care 1992;30:473-83.

32. Brazier JE, Harper R, Jones NM, et al. Validating the SF-36 health survey questionnaire: new outcome measure for primary care. BMJ 1992;305:160-4.

33. Ware JE Jr, Kosinski M, Keller SD. SF-36 physical \& mental health summary scales: a user's manual. Boston: New England Medical Center, 1994.

34. Ware JE Jr, Kosinski M, Turner-Bowker DM, et al. User's manual for the SF-12v2 health survey. Lincoln, RI: Quality Metric Incorporated, 2002.

35. Yazdany J, Trupin L, Gansky SA, et al. Brief index of lupus damage: a patient-reported measure of damage in systemic lupus erythematosus. Arthritis Care Res (Hoboken) 2011;63:1170-7.

36. Drenkard C, Yazdany J, Trupin L, et al. Validity of a self-administered version of the brief index of lupus damage in a predominantly African American systemic lupus erythematosus cohort. Arthritis Care Res (Hoboken) 2014;66:888-96.

37. Karlson EW, Daltroy LH, Rivest C, et al. Validation of a Systemic Lupus Activity Questionnaire (SLAQ) for population studies. Lupus 2003;12:280-6.

38. Pons-Estel GJ, Alarcón GS, Scofield L, et al. Understanding the epidemiology and progression of systemic lupus erythematosus. Semin Arthritis Rheum 2010;39:257-68.

39. Jolly M, Garris CP, Mikolaitis RA, et al. Development and validation of the Lupus Impact Tracker: a patient-completed tool for clinical practice to assess and monitor the impact of systemic lupus erythematosus. Arthritis Care Res (Hoboken) 2014:66:1542-50.

40. Kroenke K, Spitzer RL, Williams JB. The PHQ-9: validity of a brief depression severity measure. J Gen Intern Med 2001;16:606-13.

41. Fukuhara S, Lopes AA, Bragg-Gresham JL, et al. Health-related quality of life among dialysis patients on three continents: the Dialysis Outcomes and Practice Patterns Study. Kidney Int 2003:64:1903-10.

42. Ware JE Jr. SF-36 health survey: manual \& interpretation guide. Boston, MA: The Health Institute, New England Medical Center, 1993.

43. Goulia P, Voulgari PV, Tsifetaki N, et al. Comparison of health-related quality of life and associated psychological factors between younger and older patients with established rheumatic disorders. Aging Ment Health 2010;14:819-27.

44. Simone MJ, Appelbaum J. HIV in older adults. Geriatrics 2008;63:6-12.

45. Flacker JM. What is a geriatric syndrome anyway? J Am Geriatr Soc 2003;51:574-6.

46. Office of Disease Prevention and Health Promotion. Healthy People 2020. Washington DC: U.S. Department of Health and Human Services, 2011. https://www.healthypeople.gov

47. McElhone K, Abbott J, Gray J, et al. Patient perspective of systemic lupus erythematosus in relation to health-related quality of life concepts: a qualitative study. Lupus 2010;19:1640-7.

48. Gallop K, Nixon A, Swinburn P, et al. Development of a conceptual model of health-related quality of life for systemic lupus erythematosus from the patient's perspective. Lupus 2012;21:934-43.

49. Kane RL. The contribution of geriatric health services research to successful aging. Ann Intern Med 2003;139(Pt 2):460-2.

50. Kuriya B, Gladman DD, Ibañez D, et al. Quality of life over time in patients with systemic lupus erythematosus. Arthritis Rheum 2008:59:181-5. 